\title{
Automatically Explaining Machine Learning Predictions on Severe Chronic Obstructive Pulmonary Disease Exacerbations: Retrospective Cohort Study
}

\author{
Siyang Zeng ${ }^{1}$, MS; Mehrdad Arjomandii, ${ }^{2,3}$, MD; Gang Luo ${ }^{1}$, DPhil \\ ${ }^{1}$ Department of Biomedical Informatics and Medical Education, University of Washington, Seattle, WA, United States \\ ${ }^{2}$ Medical Service, San Francisco Veterans Affairs Medical Center, San Francisco, CA, United States \\ ${ }^{3}$ Department of Medicine, University of California, San Francisco, CA, United States
}

Corresponding Author:

Gang Luo, DPhil

Department of Biomedical Informatics and Medical Education

University of Washington

UW Medicine South Lake Union

850 Republican Street, Building C, Box 358047

Seattle, WA, 98195

United States

Phone: 12062214596

Fax: 12062212671

Email: gangluo@cs.wisc.edu

\begin{abstract}
Background: Chronic obstructive pulmonary disease (COPD) is a major cause of death and places a heavy burden on health care. To optimize the allocation of precious preventive care management resources and improve the outcomes for high-risk patients with COPD, we recently built the most accurate model to date to predict severe COPD exacerbations, which need inpatient stays or emergency department visits, in the following 12 months. Our model is a machine learning model. As is the case with most machine learning models, our model does not explain its predictions, forming a barrier for clinical use. Previously, we designed a method to automatically provide rule-type explanations for machine learning predictions and suggest tailored interventions with no loss of model performance. This method has been tested before for asthma outcome prediction but not for COPD outcome prediction.
\end{abstract}

Objective: This study aims to assess the generalizability of our automatic explanation method for predicting severe COPD exacerbations.

Methods: The patient cohort included all patients with COPD who visited the University of Washington Medicine facilities between 2011 and 2019. In a secondary analysis of 43,576 data instances, we used our formerly developed automatic explanation method to automatically explain our model's predictions and suggest tailored interventions.

Results: Our method explained the predictions for $97.1 \%(100 / 103)$ of the patients with COPD whom our model correctly predicted to have severe COPD exacerbations in the following 12 months and the predictions for 73.6\% (134/182) of the patients with COPD who had $\geq 1$ severe COPD exacerbation in the following 12 months.

Conclusions: Our automatic explanation method worked well for predicting severe COPD exacerbations. After further improving our method, we hope to use it to facilitate future clinical use of our model.

International Registered Report Identifier (IRRID): RR2-10.2196/13783

(JMIR Med Inform 2022;10(2):e33043) doi: 10.2196/33043

\section{KEYWORDS}

chronic obstructive pulmonary disease; forecasting; machine learning; patient care management 


\section{Introduction}

\section{Background}

Chronic obstructive pulmonary disease (COPD) is a leading cause of death [1] and affects $6.5 \%$ of American adults [2]. In the United States, COPD leads to 0.7 million inpatient stays and 1.5 million emergency department (ED) visits every year [2]. Severe COPD exacerbations are exacerbations that need inpatient stays or ED visits [3]. These exacerbations often result in irreversible deterioration in health status and lung function [4-9] and account for $90.3 \%$ of the US $\$ 32.1$ billion total annual medical costs of the United States associated with COPD [2,10]. Many of these exacerbations, which include $47 \%$ of inpatient stays and many ED visits because of COPD, are regarded as preventable with suitable outpatient care $[3,11]$. To reduce severe COPD exacerbations, many health care systems and health plans use predictive models to identify high-risk patients [12] for preventive care management [13]. Once a patient is enrolled in the care management program, care managers will regularly follow up with the patient on the phone to assess the patient's health status and help schedule health and related services. For patients with COPD, successful care management can cut up to $40 \%$ of their inpatient stays [14] and $27 \%$ of their ED visits [15].

As a care management program can take $\leq 3 \%$ of patients because of resource limits [16], the effectiveness of the program depends critically on the performance of the predictive model that is used. To optimize the allocation of precious care management resources and improve the outcomes for high-risk patients with COPD, we recently built the most accurate model to date to predict severe COPD exacerbations in the following 12 months [17]. Our model achieved an area under the receiver operating characteristic curve of 0.866 , a sensitivity of $56.6 \%$ (103/182), and a specificity of $91.17 \%$ (6698/7347). In comparison, to the best of our knowledge, each published prior model for this prediction target [18-51] had an area under the receiver operating characteristic curve $\leq 0.809$ and a sensitivity $<50 \%$ when the specificity was set at approximately $91 \%$. Our model is based on the machine learning algorithm of extreme gradient boosting (XGBoost) [52]. As is the case with most machine learning models, our model does not explain its predictions, forming a barrier for clinical use [53]. Offering explanations is essential for care managers to make sense of and trust the model's predictions to make care management enrollment decisions and identify suitable interventions. Currently, there is no consensus on what explanation means for machine learning predictions. In this paper, by explaining the prediction that a machine learning model makes on a patient, we mean to find $\geq 1$ rule whose left-hand side is fulfilled by the patient and whose right-hand side is consistent with the prediction. Previously, we developed a method to automatically provide rule-type explanations for any machine learning model's predictions on tabular data and suggest tailored interventions with no loss of model performance [54-58]. This method has been tested before for asthma outcome prediction but not for COPD outcome prediction.

\section{Objective}

The goal of this particular study is to assess the generalizability of our automatic explanation method for predicting severe COPD exacerbations. After further improving our method in the future, our eventual goal is that care managers can use our method to make COPD care management enrollment and intervention decisions more quickly and reliably.

\section{Methods}

\section{Ethics Approval and Study Design}

The institutional review board of the University of Washington Medicine (UWM) approved this retrospective cohort study (STUDY00000118) using administrative and clinical data.

\section{Patient Population}

In Washington state, the UWM is the largest academic health care system. The enterprise data warehouse of the UWM contains administrative and clinical data from 12 clinics and 3 hospitals. This study used the same patient cohort as our previous predictive modeling study [17]. The patient cohort included all patients with COPD who visited the UWM facilities between 2011 and 2019. As adapted from the literature [59-62], a patient was deemed to have COPD if the patient was aged at least 40 years and met at least one of the following criteria:

1. The patient had "an outpatient visit diagnosis code of COPD (International Classification of Diseases, Ninth Revision (ICD-9): 491.22, 491.21, 491.9, 491.8, 493.2x, 492.8, 496; International Classification of Diseases, Tenth Revision (ICD-10): J42, J41.8, J44.*, J43.*) followed by $\geq 1$ prescription of long-acting muscarinic antagonist (aclidinium, glycopyrrolate, tiotropium, and umeclidinium) within 6 months"

2. The patient had " $\geq 1$ ED or $\geq 2$ outpatient visit diagnosis codes of COPD (International Classification of Diseases, Ninth Revision: 491.22, 491.21, 491.9, 491.8, 493.2x, 492.8, 496; International Classification of Diseases, Tenth Revision: J42, J41.8, J44.*, J43.*)"

3. The patient had " $\geq 1$ inpatient stay discharge having a principal diagnosis code of COPD (International Classification of Diseases, Ninth Revision: 491.22, 491.21, 491.9, 491.8, 493.2x, 492.8, 496; International Classification of Diseases, Tenth Revision: J42, J41.8, J44.*, J43.*)"

4. The patient had " $\geq 1$ inpatient stay discharge having a principal diagnosis code of respiratory failure (International Classification of Diseases, Ninth Revision: 518.82, 518.81, 799.1, 518.84; International Classification of Diseases, Tenth Revision: J96.0*, J80, J96.9*, J96.2*, R09.2) and a secondary diagnosis code of acute COPD exacerbation (International Classification of Diseases, Ninth Revision: 491.22, 491.21, 493.22, 493.21; International Classification of Diseases, Tenth Revision: J44.1, J44.0)" [17].

We used one exclusion criterion: when calculating the data instances in a given year, the patients who died or had no encounter at the UWM during that year were excluded. 


\section{Data Set}

This study used the same structured data set as our previous predictive model paper [17]. The data set contained the administrative and clinical data of the patient cohort's encounters at the 12 UWM clinics and 3 UWM hospitals between 2011 and 2020.

\section{Prediction Target (Dependent or Outcome Variable)}

This study used the same prediction target as our previous predictive model [17]. For a patient with COPD and $\geq 1$ encounter at the UWM in a particular year (index year), we used patient data up to the end of the year to predict the outcome-whether the patient would have $\geq 1$ severe COPD exacerbation in the following 12 months. A severe COPD exacerbation is defined as an inpatient stay or an ED visit with a principal diagnosis of COPD (International Classification of Diseases, Ninth Revision: 491.22, 491.21, 491.9, 491.8, 493.2x, 492.8, 496; International Classification of Diseases, Tenth Revision: J42, J41.8, J44.*, J43.*).

\section{Data Preprocessing, Predictive Model, and Features (Independent Variables)}

We applied the same methods as in our previous predictive model paper [17] to perform data preprocessing. Using the upper and lower bounds provided by a clinical expert in our team, as well as the upper and lower bounds from the Guinness World Records, we pinpointed the biologically implausible values, marked them missing, and normalized each numerical feature. Our model used 229 features and the XGBoost classification algorithm [52] to make predictions. As listed in the second table in the web-based multimedia appendix of our previous paper [17], these features were calculated on the attributes in our structured data set and covered various aspects such as vital signs, diagnoses, visits, procedures, medications, laboratory tests, and patient demographics. An example feature is the number of days since the patient had the last diagnosis of acute COPD exacerbation. Each input data instance to the predictive model contained these 229 features, corresponded to a distinct patient and index year pair, and was used to predict the outcome of the patient in the following 12 months. As in our previous predictive model paper [17], the cutoff threshold for binary classification was set at the top $10 \%$ of patients with the largest predicted risk. A care management program can take $\leq 3 \%$ of patients because of resource limits [16]. After using our model to identify the top $10 \%$ of patients with the largest predicted risk and using our automatic explanation method to explain the predictions, care managers could review patient charts, consider factors such as social dimensions, and choose $\leq 3 \%$ of patients for care management enrollment. A value of $10 \%$ was chosen to strike a balance between covering a large percentage of patients who would have $\geq 1$ severe COPD exacerbation in the following 12 months and keeping the care managers' workload manageable.

\section{Review of Our Automatic Explanation Method}

\section{Overview}

Previously, we developed a method to automatically provide rule-type explanations for any machine learning model's predictions on tabular data and suggest tailored interventions with no loss of model performance [54-58]. When creating the automatic explanation function before the prediction time, our method requires $\geq 1$ expert in the function's design team to manually provide some information, such as marking the feature-value pairs that could have a positive correlation with the bad outcome value and compiling interventions for these feature-value pair items. This can typically be performed in a few man-hours. Once this information is obtained and stored in the function's knowledge base, our method can automatically explain the machine learning model's predictions and suggest tailored interventions at the prediction time.

\section{Main Idea}

Our automatic explanation method [54-58] uses 2 models at the same time to separate making predictions and providing explanations. Each model plays a different role. The first model is used to predict the outcome. This model can be any model that takes continuous and categorical features as its inputs and is typically chosen to be the model that performs the best at making predictions. The second model comprises class-based association rules $[63,64]$ mined from the training set. We use the second model to explain the first model's predictions rather than to make predictions. After we convert each continuous feature into $\geq 1$ categorical feature via automatic discretization $[63,65]$, the association rules are mined using the Apriori algorithm, whereas other standard methods such as frequent pattern growth can also be used [64]. Every rule shows that a feature pattern links to a value $z$ of the outcome variable in the form of:

$$
p_{1} \text { AND } p_{2} \text { AND ...AND } p_{k} \rightarrow z . \text { (1) }
$$

Here, each item $p_{i}(1 \leq i \leq k)$ is a feature-value pair $(x, c)$, indicating that feature $x$ has a value $c$ if $c$ is a value or a value within $c$ if $c$ is a range. The values of $k$ and $z$ can vary by rules. For the binary classification of good versus bad outcomes, $z$ is usually the bad outcome value. The rule indicates that a patient's outcome tends to take the value $z$ if the patient satisfies all of $p_{1}, p_{2}, \ldots$, and $p_{k}$. The following is an example of a rule:

The patient's last diagnosis of acute COPD exacerbation was from the past 81.4 days AND the patient's COPD reliever prescriptions in the past year included $>10$ distinct medications $\rightarrow$ The patient will probably have at least one severe COPD exacerbation in the following 12 months.

\section{Mining and Pruning Rules}

Each rule has two quality measures: commonality and confidence. For a rule:

$$
p_{1} \text { AND } p_{2} \text { AND...AND } p_{k} \rightarrow z, \text { (1) }
$$

its commonality is defined as the percentage of data instances satisfying $p_{1}, p_{2}, \ldots$, and $p_{k}$ among all the data instances linked to $z$. Its confidence is defined as the percentage of data instances linked to $z$ among all the data instances satisfying $p_{1}, p_{2}, \ldots$, and $p_{k}$. Commonality measures the coverage of a rule within the context of $z$. Confidence measures the precision of a rule. 
The process of mining and pruning rules is controlled by five parameters: the number of top features that are used to form rules, upper limit of the number of items on the left-hand side of a rule, lower limit of confidence, lower limit of commonality, and upper limit of the confidence difference. Our method uses rules that each contains at most the upper limit number of items on its left-hand side, has a commonality that is greater than or equal to the lower limit of commonality, and has a confidence that is greater than or equal to the lower limit of confidence.

Our automatic explanation method is intended to be used for real-time clinical decision support. Once the first model provides its predicted outcome of a patient, we need to use the second model to provide automatic explanations for the prediction quickly, ideally within a subsecond. For this purpose, we need to control the number of association rules in the second model to help reduce the overhead of retrieving and ranking the relevant rules at the prediction time. We used the following three techniques to cut the number of rules:

1. Some machine learning algorithms, such as XGBoost [52], automatically calculate the importance value of each feature. When the data set included many features, we used only the top few features in the first model with the highest importance values to form rules. Usually, we set the number of top features to be used to the maximum possible number without making the association rule mining process run out of memory.

2. A rule $r_{1}$ was dropped if there exists another rule $r_{2}$ satisfying three conditions: $r_{1}$ and $r_{2}$ have the same value on their right-hand sides; the items on the left-hand side of $r_{2}$ are a proper subset of the items on the left-hand side of $r_{1}$ (ie, $r_{2}$ is more general than $r_{1}$ ); and the confidence of $r_{2}$ is greater than or equal to the confidence of $r_{l}-$ the upper limit of the confidence difference.

3. All distinct feature-value pairs were examined and labeled by a clinical expert in the automatic explanation function's design team. When forming rules, we used only those feature-value pairs that the clinical expert deemed could have a positive correlation with the bad outcome value.

For every feature-value pair item used to form association rules, a clinical expert in the automatic explanation function's design team compiled $\geq 0$ intervention. An item is termed actionable if it is associated with $\geq 1$ intervention. These interventions are automatically attached to the rules whose left-hand sides contain this item. A rule is termed actionable if its left-hand side contains $\geq 1$ actionable item and, in turn, is associated with $\geq 1$ intervention. In theory, for each combination of feature-value pair items that appears on the left-hand side of $\geq 1$ mined rule, the clinical expert could compile additional interventions to be automatically attached to the rules whose left-hand sides contain this combination if these interventions have not already been compiled for any individual feature-value pair item in the combination. In practice, we have not needed to do this for predicting severe COPD exacerbations, whereas such a need could occur in some other clinical prediction tasks in the future.

\section{Explaining the Predictions}

For each patient predicted by the first model to have a bad outcome, we explained the prediction by presenting the association rules in the second model whose left-hand sides are fulfilled by the patient and whose right-hand sides have the bad outcome value. The rules were sorted using the method given in our paper [57]. This method incorporates 5 factors into a rule-scoring function, striking a balance among them. These factors include confidence, commonality, number of items on the left-hand side of the rule, whether the rule is actionable, and the degree of information redundancy with the higher-ranked rules. The rules are ranked based on the computed scores in an iterative fashion. Every rule offers an explanation for why the patient is predicted to have a bad outcome. For each actionable rule that is presented, the associated interventions are shown next to it. This helps the user of the automatic explanation function pinpoint suitable interventions for the patient. Typically, the rules in the second model provide common reasons for a patient to have a bad outcome. Although some patients could have bad outcomes because of rare reasons not covered by these rules, the second model usually explains most, although not all, of the bad outcomes correctly predicted by the first model.

\section{Parameter Setting}

Our model [17] used 229 features to predict patient outcomes. In this study, we used the top 80 features that our model ranked with the highest importance values to form association rules. Regardless of whether all 229 features or only the top 80 features were used, our model had the same area under the receiver operating characteristic curve of 0.866 .

As in our prior study on automatically explaining predictions of asthma outcomes on the UWM data [55], we set the upper limit of the number of items on the left-hand side of a rule to 5 , the lower limit of commonality to $1 \%$, and the lower limit of confidence to $50 \%$. The last 2 values were commonly used to mine association rules [63], whereas commonality was essentially support computed on all the data instances linked to the bad outcome [54]. The first value struck a balance between the explanation power of our automatic explanation method and not making the rules too complex to understand. To set the upper limit value of the confidence difference, we plotted the number of association rules remaining from the rule pruning process versus the upper limit of the confidence difference. Our prior automatic explanation papers [54-56,58] showed that the number of remaining rules first decreased rapidly as the upper limit of the confidence difference increased and then slowly decreased after the upper limit of the confidence difference became large enough. The upper limit value of the confidence difference was set at a point where a further increase in the confidence difference had a minor impact on reducing the number of remaining rules.

\section{Data Analysis}

\section{Split of the Training and Test Sets}

We adopted the method from our previous predictive model paper [17] to split the entire data set into the training and test sets. As the outcomes were from the following year, the data 
set contained 9 years of effective data (2011-2019) over the 10 -year period of 2011 to 2020 . To reflect how our predictive model and our automatic explanation method will be used in clinical practice in the future, we used the 2011 to 2018 data as the training set to train our model and compute the association rules used by our automatic explanation method and the 2019 data as the test set to assess the performance of our model and our automatic explanation method.

\section{Providing Examples of Automatic Explanations}

To give the reader a concrete feeling of the results produced by our automatic explanation method, we randomly selected 3 example patients from the patients who were correctly predicted by our model to have $\geq 1$ severe COPD exacerbation in the following 12 months and for whom our automatic explanation method could offer $\geq 1$ explanation. For each example patient, we listed the top 3 explanations given by our automatic explanation method.

\section{Performance Metrics}

We examined the performance of our automatic explanation method using the following performance metrics from our prior automatic explanation papers [54-56,58]. Regarding the explanation power of our automatic explanation method, a performance metric is the percentage of patients for whom our method could provide explanations among the patients with COPD who were correctly predicted by our model to have $\geq 1$ severe COPD exacerbation in the following 12 months. We assessed both the average and median number of (actionable) rules matching such a patient. A rule matches a patient if the patient satisfies all items on its left-hand side.

As shown by our prior automatic explanation papers [54-56,58], many rules matching a patient often differ from each other by only 1 item on their left-hand sides. In this case, the number of rules greatly exceeded the amount of nonrepeated information contained in these rules. To provide a comprehensive overview of the amount of information provided by the automatic explanations, we examined the distributions of (1) the number of (actionable) rules and (2) the number of unique actionable items in the rules matching a patient who was correctly predicted by our model to have $\geq 1$ severe COPD exacerbation in the following 12 months.

\section{Results}

\section{Characteristics of Our Patient Cohort}

Each data instance corresponds to a distinct patient and index year pair. Tables 1 and 2 summarize the patient demographic and clinical characteristics of the data instances in the training and test sets, respectively. These 2 sets of characteristics were relatively similar to each other. In the training set, $5.66 \%$ (2040/36,047) of the data instances were related to severe COPD exacerbations in the following 12 months. In the test set, $2.42 \%$ (182/7529) of the data instances were related to severe COPD exacerbations in the following 12 months. A detailed comparison of these 2 sets of characteristics was provided in our previous predictive model paper [17]. 
Table 1. The patient demographic and clinical characteristics of the data instances in the training set.

\begin{tabular}{llll}
\hline Patient characteristics & $\begin{array}{l}\text { Data instances related to no severe COPD } \\
\text { exacerbation in the following 12 months } \\
(\mathrm{n}=34,007), \mathrm{n}(\%)\end{array}$ & $\begin{array}{l}\text { Data instances related to severe COPD } \\
\text { exacerbations in the following 12 months } \\
(\mathrm{n}=2040), \mathrm{n}(\%)\end{array}$ & $\begin{array}{l}\text { Data instances } \\
(\mathrm{n}=36,047), \mathrm{n}(\%)\end{array}$ \\
\hline
\end{tabular}

\section{Sex}

$\begin{array}{ll}\text { Female } & 14,665(43.12) \\ \text { Male } & 19,342(56.88)\end{array}$

749 (36.72)

15,414 (42.76)

Age (years)

$\begin{array}{ll}40-65 & 17,574(51.68) \\ >65 & 16,433(48.32)\end{array}$

$1291(63.28)$

20,633 (57.24)

Race

White

Black or African American

Asian

American Indian or Alaska Native

Native Hawaiian or other Pacific

Islander

Other, unknown, or not reported

Ethnicity

$\begin{array}{ll}\text { Hispanic } & 804(2.36) \\ \text { Non-Hispanic } & 30,644(90.11) \\ \text { Unknown or not reported } & 2559(7.53)\end{array}$

Insurance

Public

$27,831(81.84)$

Private

$16,679(49.05)$

Self-paid or charity

1765 (5.19)

Number of years since the first encounter related to COPD in the data set

$\leq 3$

$>3$

\section{Smoking status}

$\begin{array}{ll}\text { Current smoker } & 15,863(46.65) \\ \text { Former smoker } & 7022(20.65) \\ \text { Never smoker or unknown } & 11,122(32.7)\end{array}$

\section{COPD medication prescription}

\begin{tabular}{|c|c|}
\hline $\mathrm{SABA}^{\mathrm{b}}$ & $20,865(61.36)$ \\
\hline SAMA $^{\mathrm{c}}$ & $8566(25.19)$ \\
\hline SABA and SAMA combination & $6364(18.71)$ \\
\hline LABA $^{d}$ & $8062(23.71)$ \\
\hline LAMA $^{\mathrm{e}}$ & $9242(27.18)$ \\
\hline LABA and LAMA combination & $386(1.14)$ \\
\hline $\operatorname{ICS}^{\mathrm{f}}$ & $12,208(35.9)$ \\
\hline ICS and LABA combination & $7544(22.18)$ \\
\hline $\begin{array}{l}\text { ICS, LABA, and LAMA combina- } \\
\text { tion }\end{array}$ & $16(0.05)$ \\
\hline
\end{tabular}

1219 (59.75)

$821(40.25)$

$18,793(52.13)$

$17,254(47.87)$

$1330(65.2)$

27,447 (76.14)

524 (25.69)

144 (7.06)

$26(1.27)$

$8(0.39)$

$8(0.39)$

4795 (13.3)

2092 (5.8)

713 (1.98)

$184(0.51)$

816 (2.27)

53 (2.6)

857 (2.38)

1941 (95.15)

46 (2.25)

32,585 (90.39)

2605 (7.23)

1767 (86.62)

29,598 (82.11)

834 (40.88)

17,513 (48.58)

229 (11.23)

1994 (5.53)

1566 (76.76)

30,315 (84.1)

474 (23.24)

5732 (15.90)

1089 (53.38)

$16,952(47.03)$

345 (16.91)

606 (29.71)

7367 (20.44)

$11,728(32.53)$

$1684(82.55)$

$22,549(62.55)$

$1042(51.08)$

9608 (26.65)

810 (39.71)

7174 (19.9)

842 (41.27)

8904 (24.7)

1001 (49.07)

10,243 (28.42)

40 (1.96)

426 (1.18)

$1119(54.85)$

13,327 (36.97)

782 (38.33)

8326 (23.1)

$0(0)$

$16(0.04)$ 


\begin{tabular}{|c|c|c|c|}
\hline Patient characteristics & $\begin{array}{l}\text { Data instances related to no severe } \mathrm{COPD}^{\mathrm{a}} \\
\text { exacerbation in the following } 12 \text { months } \\
(\mathrm{n}=34,007), \mathrm{n}(\%)\end{array}$ & $\begin{array}{l}\text { Data instances related to severe COPD } \\
\text { exacerbations in the following } 12 \text { months } \\
(n=2040), n(\%)\end{array}$ & $\begin{array}{l}\text { Data instances } \\
(\mathrm{n}=36,047), \mathrm{n}(\%)\end{array}$ \\
\hline Systemic corticosteroid & $10,149(29.84)$ & $1144(56.08)$ & $11,293(31.33)$ \\
\hline Phosphodiesterase-4 inhibitor & $84(0.25)$ & $10(0.49)$ & $94(0.26)$ \\
\hline \multicolumn{4}{|l|}{ Comorbidity } \\
\hline Anxiety or depression & $10,061(29.59)$ & $725(35.54)$ & $10,786(29.92)$ \\
\hline Allergic rhinitis & $2271(6.68)$ & $174(8.53)$ & $2445(6.78)$ \\
\hline Asthma & $4377(12.87)$ & $417(20.44)$ & $4794(13.3)$ \\
\hline Diabetes & $7177(21.1)$ & $446(21.86)$ & $7623(21.15)$ \\
\hline Congestive heart failure & $5568(16.37)$ & $495(24.26)$ & $6063(16.82)$ \\
\hline Eczema & $1460(4.29)$ & $98(4.8)$ & $1558(4.32)$ \\
\hline Hypertension & $17,211(50.61)$ & $1150(56.37)$ & $18,361(50.94)$ \\
\hline Gastroesophageal reflux & $6655(19.57)$ & $507(24.85)$ & $7162(19.87)$ \\
\hline Ischemic heart disease & $6934(20.39)$ & $486(23.82)$ & $7420(20.58)$ \\
\hline Obesity & $3232(9.5)$ & $255(12.5)$ & $3487(9.67)$ \\
\hline Lung cancer & $742(2.18)$ & $52(2.55)$ & $794(2.2)$ \\
\hline Sleep apnea & $2926(8.6)$ & $253(12.4)$ & $3179(8.82)$ \\
\hline Sinusitis & $1299(3.82)$ & $83(4.07)$ & $1382(3.83)$ \\
\hline
\end{tabular}

${ }^{\mathrm{a} C O P D}$ : chronic obstructive pulmonary disease.

${ }^{\text {b}}$ SABA: short-acting beta-2 agonist.

${ }^{\mathrm{c}} \mathrm{SAMA}$ : short-acting muscarinic antagonist.

${ }^{\mathrm{d}}$ LABA: long-acting beta-2 agonist.

eAMA: long-acting muscarinic antagonist.

fICS: inhaled corticosteroid. 
Table 2. The patient demographic and clinical characteristics of the data instances in the test set.

\begin{tabular}{|c|c|c|c|}
\hline Patient characteristics & $\begin{array}{l}\text { Data instances related to no severe COPD } \\
\text { exacerbation in the following } 12 \text { months } \\
(\mathrm{n}=7347), \mathrm{n}(\%)\end{array}$ & $\begin{array}{l}\text { Data instances related to severe COPD } \\
\text { exacerbations in the following } 12 \text { months } \\
(\mathrm{n}=182), \mathrm{n}(\%)\end{array}$ & $\begin{array}{l}\text { Data instances } \\
(\mathrm{n}=7529), \mathrm{n}(\%)\end{array}$ \\
\hline \multicolumn{4}{|l|}{ Sex } \\
\hline Female & $3242(44.13)$ & $47(25.8)$ & $3289(43.68)$ \\
\hline Male & $4105(55.87)$ & $135(74.2)$ & $4240(56.32)$ \\
\hline \multicolumn{4}{|l|}{ Age (years) } \\
\hline $40-65$ & $3324(45.24)$ & $118(64.8)$ & $3442(45.72)$ \\
\hline$>65$ & $4023(54.76)$ & $64(35.2)$ & $4087(54.28)$ \\
\hline \multicolumn{4}{|l|}{ Race } \\
\hline White & $5682(77.34)$ & $111(61.0)$ & $5793(76.94)$ \\
\hline Black or African American & $839(11.42)$ & $57(31.3)$ & $896(11.9)$ \\
\hline Asian & $432(5.88)$ & $7(3.9)$ & $439(5.83)$ \\
\hline American Indian or Alaska Native & $151(2.06)$ & $5(2.7)$ & $156(2.07)$ \\
\hline $\begin{array}{l}\text { Native Hawaiian or other Pacific } \\
\text { Islander }\end{array}$ & $51(0.69)$ & $2(1.1)$ & $53(0.71)$ \\
\hline Other, unknown, or not reported & $192(2.61)$ & $0(0.0)$ & $192(2.55)$ \\
\hline \multicolumn{4}{|l|}{ Ethnicity } \\
\hline Hispanic & $185(2.52)$ & $3(1.6)$ & $188(2.5)$ \\
\hline Non-Hispanic & $6909(94.04)$ & $179(98.4)$ & $7088(94.14)$ \\
\hline Unknown or not reported & $253(3.44)$ & $0(0)$ & $253(3.36)$ \\
\hline \multicolumn{4}{|l|}{ Insurance } \\
\hline Public & $6722(91.49)$ & $179(98.4)$ & $6901(91.66)$ \\
\hline Private & $4532(61.69)$ & $110(60.4)$ & $4642(61.65)$ \\
\hline Self-paid or charity & $499(6.79)$ & $41(22.5)$ & $540(7.17)$ \\
\hline \multicolumn{4}{|c|}{ Number of years since the first encounter related to COPD in the data set } \\
\hline$\leq 3$ & $5073(69.05)$ & $81(44.5)$ & $5154(68.46)$ \\
\hline$>3$ & $2274(30.95)$ & $101(55.5)$ & $2375(31.54)$ \\
\hline \multicolumn{4}{|l|}{ Smoking status } \\
\hline Current smoker & $3781(51.46)$ & $112(61.5)$ & $3893(51.71)$ \\
\hline Former smoker & $1242(16.91)$ & $25(13.7)$ & $1267(16.83)$ \\
\hline Never smoker or unknown & $2324(31.63)$ & $45(24.7)$ & $2369(31.47)$ \\
\hline \multicolumn{4}{|l|}{ COPD medication prescription } \\
\hline SABA ${ }^{b}$ & $4083(55.57)$ & $158(86.8)$ & $4241(56.33)$ \\
\hline SAMA $^{\mathrm{c}}$ & $1134(15.43)$ & $68(37.4)$ & $1202(15.96)$ \\
\hline SABA and SAMA combination & $1694(23.06)$ & $115(63.2)$ & $1809(24.03)$ \\
\hline $\mathrm{LABA}^{\mathrm{d}}$ & $1683(22.91)$ & $77(42.3)$ & $1760(23.38)$ \\
\hline LAMA $^{\mathrm{e}}$ & $1951(26.56)$ & $110(60.4)$ & $2061(27.37)$ \\
\hline LABA and LAMA combination & $388(5.28)$ & $12(6.6)$ & $400(5.31)$ \\
\hline $\operatorname{ICS}^{\mathrm{f}}$ & $2537(34.53)$ & $98(53.8)$ & $2635(35)$ \\
\hline ICS and LABA combination & $1729(23.53)$ & $75(41.2)$ & $1804(23.96)$ \\
\hline $\begin{array}{l}\text { ICS, LABA, and LAMA combina- } \\
\text { tion }\end{array}$ & $68(0.93)$ & $1(0.5)$ & $69(0.92)$ \\
\hline
\end{tabular}




\begin{tabular}{llll}
\hline Patient characteristics & $\begin{array}{l}\text { Data instances related to no severe COPD } \\
\text { exacerbation in the following 12 months } \\
(\mathrm{n}=7347), \mathrm{n}(\%)\end{array}$ & $\begin{array}{l}\text { Data instances related to severe COPD } \\
\text { exacerbations in the following 12 months } \\
(\mathrm{n}=182), \mathrm{n}(\%)\end{array}$ & $\begin{array}{l}\text { Data instances } \\
(\mathrm{n}=7529), \mathrm{n}(\%)\end{array}$ \\
\hline $\begin{array}{l}\text { Systemic corticosteroid } \\
\text { Phosphodiesterase-4 inhibitor }\end{array}$ & $2282(31.06)$ & $103(56.6)$ & $2385(31.68)$ \\
Comorbidity & $24(0.33)$ & $2(1.1)$ & $26(0.35)$ \\
Anxiety or depression & $2090(28.45)$ & $63(34.6)$ & $4153(28.6)$ \\
Allergic rhinitis & $396(5.39)$ & $14(7.7)$ & $1096(14.56)$ \\
Asthma & $1053(14.33)$ & $43(23.6)$ & $1689(22.43)$ \\
Diabetes & $1649(22.44)$ & $40(22)$ & $1412(18.75)$ \\
Congestive heart failure & $1369(18.63)$ & $43(23.6)$ & $258(3.43)$ \\
Eczema & $247(3.36)$ & $11(6)$ & $3791(50.35)$ \\
Hypertension & $3686(50.17)$ & $105(57.7)$ & $1443(19.17)$ \\
Gastroesophageal reflux & $1396(19)$ & $47(25.8)$ & $1658(22.02)$ \\
Ischemic heart disease & $1604(21.83)$ & $54(29.7)$ & $669(8.89)$ \\
Obesity & $648(8.82)$ & $21(11.5)$ & $3(1.6)$ \\
Lung cancer & $200(2.72)$ & $28(15.4)$ & $7(3.8)$ \\
Sleep apnea & $887(12.07)$ & $272(3.7)$ & $203(2.7)$ \\
Sinusitis & & & $915(12.15)$ \\
\hline
\end{tabular}

${ }^{\mathrm{a} C O P D}$ : chronic obstructive pulmonary disease.

${ }^{\text {b}}$ SABA: short-acting beta-2 agonist.

${ }^{\mathrm{c}} \mathrm{SAMA}$ : short-acting muscarinic antagonist.

${ }^{\mathrm{d}}$ LABA: long-acting beta- 2 agonist.

${ }^{\text {e}}$ LAMA: long-acting muscarinic antagonist.

${ }^{\mathrm{f}}$ ICS: inhaled corticosteroid.

\section{The Number of Association Rules}

Using the top 80 features ranked with the highest importance values in our predictive model, 7,729,134 association rules were mined from the training set. Figure 1 shows the number of remaining rules versus the upper limit of the confidence difference. The number of remaining rules first rapidly decreased as the upper limit of the confidence difference increased and then slowly decreased after the upper limit of the confidence difference became $\geq 0.15$. We set the upper limit of the confidence difference to the value of 0.15 , resulting in 492,803 remaining rules.

Figure 1. The number of remaining association rules versus the upper limit of the confidence difference.

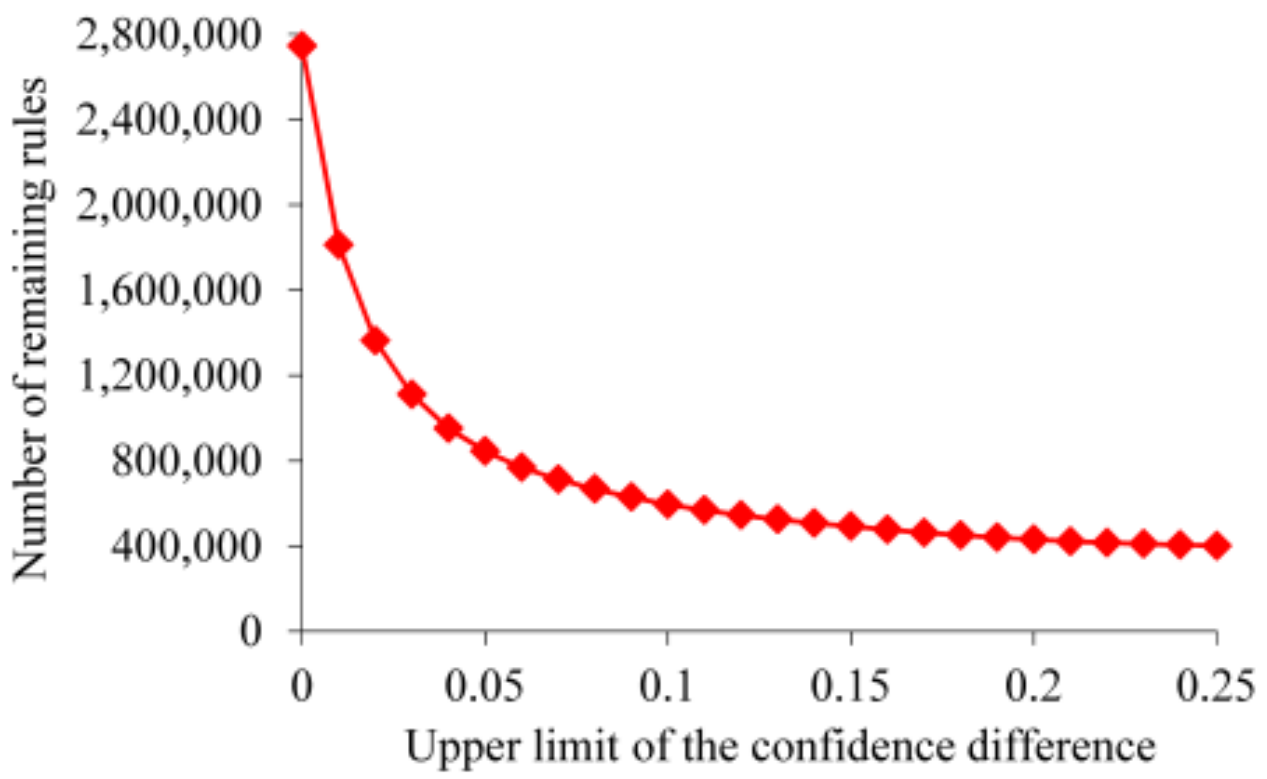


The top 80 features totally had 219 distinct feature-value pairs, $141(64.4 \%)$ of which were actionable. A clinical expert on COPD (MA) in our team reviewed all distinct feature-value pairs of the top 80 features and labeled those that could have a positive correlation with severe COPD exacerbations in the following 12 months. After dropping the rules containing any other feature-value pair items, 460,592 rules were left. These rules were all actionable.

\section{Examples of the Produced Automatic Explanations}

To give the reader a concrete feeling of the results produced by our automatic explanation method, we randomly selected 3 example patients from the patients who were correctly predicted by our model to have $\geq 1$ severe COPD exacerbation in the following 12 months and for whom our automatic explanation method could offer $\geq 1$ explanation. Tables 3-5 show the top 3 explanations that our automatic explanation method provided for every example patient. 
Table 3. The top 3 association rules generated for the first example patient.

Rank, rule, and item on the Interpretation of the item Interventions linked to the item

rule's left-hand side

Rank 1: The patient's last diagnosis of acute COPD ${ }^{\mathrm{a}}$ exacerbation was from the past 81.4 days AND the patient's COPD reliever prescriptions in the past year included $>10$ distinct medications $\rightarrow$ the patient will probably have at least one severe COPD exacerbation in the following 12 months

The patient's last diagnosis of acute COPD exacerbation was from the disease. the past 81.4 days

The patient's COPD reliever prescriptions in the past year included $>10$ distinct medications
Having a recent acute COPD exacerbation shows a need for better control of

Using many rescue medications for COPD indicates ineffective regimen, poor treatment adherence, or poor control of the disease.
Provide education on managing COPD and more frequent follow-ups Ensure use of appropriate COPD medications

- Consider influenza shot, pneumonia vaccination, or smoking cessation

- Assess the need for pulmonary rehabilitation or home care

- Ensure that the patient has a primary care provider or is referred to a specialist

- Simplify COPD medications to once-a-day formulations or combination medications

- Address concerns for adverse interactions between medications

- Provide education on the correct use of COPD medications or inhalers

- Consider strategies to improve medication adherence such as providing reminders for taking medications in time

- Medication reconciliation review by a physician or a pharmacist

Rank 2: The patient had between 8 and 19 diagnoses of acute COPD exacerbation in the past year AND the patient's last COPD diagnosis was from the past 25.6 days AND the patient's nebulizer medication prescriptions in the past year included $>11$ medications $\rightarrow$ the patient will probably have at least one severe COPD exacerbation in the following 12 months

The patient had between 8 and 19 diagnoses of acute COPD exacerbation in the past year

The patient's last COPD diagnosis was from the past 25.6 days

The patient's nebulizer medication prescriptions in the past year included $>11$ medications

Frequently having acute COPD exacerbations shows a need for better control of the disease.

Having a recent COPD diagnosis associated with an $\mathrm{ED}^{\mathrm{b}}$ visit or an inpatient stay indicates poor control of the disease.

Using many medications for COPD with a nebulizer indicates an ineffective regimen, poor treatment adherence, or poor control of the disease. Using nebulizer medications could be a sign of having a mild exacerbation or more severe COPD.
- $\quad$ Provide education on managing COPD and more frequent follow-ups

- Ensure use of appropriate COPD medications

- Consider influenza shot, pneumonia vaccination, or smoking cessation

- Assess the need for pulmonary rehabilitation or home care

- Provide education on managing COPD and more frequent follow-ups - Ensure use of appropriate COPD medications

- Consider influenza shot, pneumonia vaccination, or smoking cessation

- Assess the need for pulmonary rehabilitation or home care

- Simplify COPD medications to once-a-day formulations or combination medications

- Address concerns for adverse interactions between medications

- Provide education on the correct use of COPD medications or inhalers

- Consider strategies to improve medication adherence such as providing reminders for taking medications in time

- Medication reconciliation review by a physician or a pharmacist

Rank 3: The patient's average length of an inpatient stay in the past year was between 0.61 and 7.66 days AND the patient's last outpatient visit on COPD occurred in the past 82.4 days AND the patient's nebulizer medication prescriptions in the past year included >11 medications AND the patient's maximum percentage of neutrophils in the past year was $>76.5 \% \rightarrow$ the patient will probably have at least one severe COPD exacerbation in the following 12 months

The patient's average length of an inpatient stay in the past year was between 0.61 and 7.66 days

The patient's last outpatient visit on COPD occurred in the past 82.4 days

The patient's nebulizer medication prescriptions in the past year included $>11$ medications
Having a long inpatient stay can indicate that the patient has a more severe disease or comorbidities.

If the patient's last outpatient visit on COPD was for acute problems with COPD, it could indicate poor control of the disease and a need for additional support to control COPD.

Using many medications for COPD with a nebulizer indicates an ineffective regimen, poor treatment adherence, or poor control of the disease. Using nebulizer medications could be a sign of having a mild exacerbation or more severe COPD.
- Ensure that the patient has a primary care provider

- Assess the need for home care or referral to a skilled nursing facility

- $\quad$ Provide education on managing COPD and resources for care

- $\quad$ Ensure use of appropriate COPD medications

- $\quad$ Provide education on managing COPD and resources for care

- Ensure use of appropriate COPD medications

- Assess the need for home care or pulmonary rehabilitation

- Simplify COPD medications to once-a-day formulations or combination medications

- Address concerns for adverse interactions between medications

- Provide education on the correct use of COPD medications or inhalers

- Consider strategies to improve medication adherence such as providing reminders for taking medications in time

- Medication reconciliation review by a physician or a pharmacist 
Rank, rule, and item on the Interpretation of the item rule's left-hand side

The patient's maximum Having a large percentage of neu-

percentage of neu-

trophils in the past year tress.

was $>76.5 \%$
Interventions linked to the item

- Evaluate the respiratory system, for example, using radiographic imaging

- Consider doing diagnostic tests such as viral panel, sputum culture, or procalcitonin

- Evaluate other potential morbidities such as cardiovascular disease with an electrocardiogram, echocardiography, or laboratory tests such as brain natriuretic peptide or D-dimer

${ }^{\mathrm{a} C O P D}$ : chronic obstructive pulmonary disease.

${ }^{b}$ ED: emergency department. 
Table 4. The top 3 association rules generated for the second example patient.

Rank, rule, and item on the Interpretation of the item Interventions linked to the item

rule's left-hand side

Rank 1: The patient's last diagnosis of acute COPD ${ }^{\mathrm{a}}$ exacerbation was from the past 81.4 days AND the patient had $>2 \mathrm{ED}^{\mathrm{b}}$ visits in the past 6 months AND the patient's nebulizer medication prescriptions in the past year included $>11$ medications $\rightarrow$ the patient will probably have at least one severe COPD exacerbation in the following 12 months

The patient's last diagnosis of acute COPD the past 81.4 days exacerbation was from the disease.
Having a recent acute COPD exacerbation shows a need for better control of
•
Provide education on managing COPD and more frequent follow-ups Ensure use of appropriate COPD medications

- Consider influenza shot, pneumonia vaccination, or smoking cessation

- Assess the need for pulmonary rehabilitation or home care

- Ensure that the patient has a primary care provider or is referred to a specialist

The patient had $>2$ ED visits in the past 6 months

Using the ED indicates poor control of conditions or a lack of access to primary, specialty, or home care.

Provide education on managing COPD and more frequent follow-ups Ensure use of appropriate COPD medications

- Consider influenza shot, pneumonia vaccination, or smoking cessation
- Assess the need for pulmonary rehabilitation or home care

- Ensure that the patient has a primary care provider or is referred to a specialist

The patient's nebulize medication prescriptions in the past year included $>11$ medications
Using many medications for COPD with a nebulizer indicates an ineffective regimen, poor treatment adherence, or poor control of the disease. Using nebulizer medications could be a sign of having a mild exacerbation or more severe COPD.
- Simplify COPD medications to once-a-day formulations or combination medications

- Address concerns for adverse interactions between medications

- Provide education on the correct use of COPD medications or inhalers reminders for taking medications in time

- Medication reconciliation review by a physician or a pharmacist
- Consider strategies to improve medication adherence such as providing

Rank 2: The patient's maximum BMI in the past year was <22.81 AND the patient's last ED visit related to COPD occurred no less than 27.2 days ago and no more than 94.3 days ago AND the patient's average length of stay of an ED visit in the past year was between 0.03 and 0.29 day AND the patient had between 2 and 4 encounters related to acute COPD exacerbation or respiratory failure in the past year $\rightarrow$ the patient will probably have at least one severe COPD exacerbation in the following 12 months

\begin{abstract}
The patient's maximum BMI in the past year was $<22.81$

The patient's last ED visit related to COPD occurred no less than 27.2 days ago and no more than 94.3 days ago
\end{abstract}

The patient's average length of stay of an ED visit in the past year was between 0.03 and 0.29 day

The patient had between 2 and 4 encounters related to acute COPD exacerbation or respiratory failure in the past year
Having an unintentional weight loss can indicate comorbidities or other complications, such as malnutrition or metabolic syndrome.

Having a recent ED visit related to COPD shows a need for better control of the disease.

Using the ED indicates poor control of conditions or a lack of access to primary, specialty, or home care.

Frequently having acute COPD exacerbations or respiratory failures shows a need for better control of the disease.
- Optimize nutritional status to address low BMI

- Provide dietary education and advise appropriate exercise
Rank 3: The patient had between 3 and 5 ED visits in the past year AND the patient's minimum $\mathrm{SpO}_{2}{ }^{\mathrm{c}}$ in the past year was between $17 \%$ and $89.5 \%$ AND the patient's maximum percentage of neutrophils in the past year was $>76.5 \%$ AND the patient smoked $>0.48$ pack of cigarettes per day in the past year $\rightarrow$ the patient will probably have at least one severe COPD exacerbation in the following 12 months 


\begin{tabular}{|c|c|c|}
\hline $\begin{array}{l}\text { Rank, rule, and item on the } \\
\text { rule's left-hand side }\end{array}$ & Interpretation of the item & Interventions linked to the item \\
\hline $\begin{array}{l}\text { The patient had be- } \\
\text { tween } 3 \text { and } 5 \text { ED visits } \\
\text { in the past year }\end{array}$ & $\begin{array}{l}\text { Using the ED indicates poor control of } \\
\text { conditions or a lack of access to prima- } \\
\text { ry, specialty, or home care. }\end{array}$ & 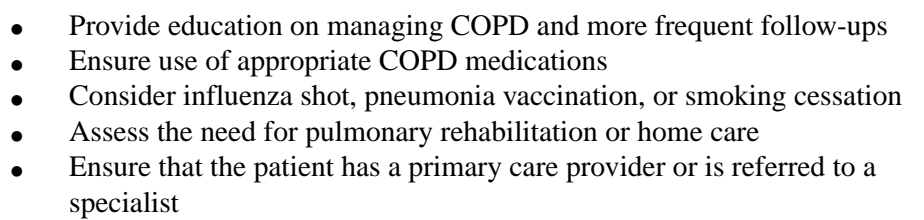 \\
\hline $\begin{array}{l}\text { The patient's minimum } \\
\mathrm{SpO}_{2} \text { in the past year } \\
\text { was between } 17 \% \text { and } \\
89.5 \%\end{array}$ & $\begin{array}{l}\text { Having a low } \mathrm{SpO}_{2} \text { indicates worsen- } \\
\text { ing of symptoms or other complications } \\
\text { such as hypoxemia. }\end{array}$ & $\begin{array}{l}\text { - } \quad \text { Evaluate for cardiopulmonary causes of hypoxemia } \\
\text { - Consider nighttime oximetry or sleep study to evaluate for nighttime hy- } \\
\text { poxemia or sleep apnea } \\
\text { - Assess the need for home oxygen or nighttime noninvasive ventilation }\end{array}$ \\
\hline $\begin{array}{l}\text { The patient's maximum } \\
\text { percentage of neu- } \\
\text { trophils in the past year } \\
\text { was }>76.5 \%\end{array}$ & $\begin{array}{l}\text { Having a large percentage of neu- } \\
\text { trophils can indicate infections or dis- } \\
\text { tress. }\end{array}$ & $\begin{array}{l}\text { - Evaluate the respiratory system, for example, using radiographic imaging } \\
\text { - Consider doing diagnostic tests such as viral panel, sputum culture, or } \\
\text { procalcitonin } \\
\text { Evaluate other potential morbidities such as cardiovascular disease with } \\
\text { an electrocardiogram, echocardiography, or laboratory tests such as brain } \\
\text { natriuretic peptide or D-dimer }\end{array}$ \\
\hline $\begin{array}{l}\text { The patient smoked } \\
>0.48 \text { pack of cigarettes } \\
\text { per day in the past year }\end{array}$ & $\begin{array}{l}\text { Smoking is a key risk factor for COPD } \\
\text { complications. }\end{array}$ & $\begin{array}{l}\text { - } \quad \text { Provide education on the health risks of smoking } \\
\text { - } \quad \text { Suggest and provide support for smoking cessation }\end{array}$ \\
\hline
\end{tabular}

${ }^{\mathrm{a} C O P D}$ : chronic obstructive pulmonary disease.

${ }^{b}$ ED: emergency department.

${ }^{c} \mathrm{~S}_{\mathrm{P}} \mathrm{O}_{2}$ : peripheral capillary oxygen saturation. 
Table 5. The top 3 association rules generated for the third example patient.

Rank, rule, and item on the Interpretation of the item Interventions linked to the item

rule's left-hand side

Rank 1: The patient had between 24 and 49 COPD $^{\mathrm{a}}$ diagnoses in the past year AND the patient had >11 nebulizer medication prescriptions in the past year AND the patient is Black or an African American $\rightarrow$ the patient will probably have at least one severe COPD exacerbation in the following 12 months

The patient had between 24 and 49 COPD diagnoses in the past year

Frequently receiving COPD diagnoses indicates poor control of the disease.

The patient had $>11$ nebulizer medication prescriptions in the past year

Using many medications for COPD with a nebulizer indicates an ineffective regimen, poor treatment adherence, or poor control of the disease. Using nebulizer medications could be a sign of having a mild exacerbation or more severe COPD.

The patient is a Black or an African American

Poor respiratory outcomes and low quality of life are more prevalent in Black and African American patients.

- $\quad$ Provide education on managing COPD and more frequent follow-ups - Ensure use of appropriate COPD medications

- Consider influenza shot, pneumonia vaccination, or smoking cessation

- Assess the need for pulmonary rehabilitation or home care

- Simplify COPD medications to once-a-day formulations or combination medications

- Address concerns for adverse interactions between medications

- Provide education on the correct use of COPD medications or inhalers

- Consider strategies to improve medication adherence such as providing reminders for taking medications in time

- Medication reconciliation review by a physician or a pharmacist

- Ensure that the patient has needed resources and access to care

- Assess the need for social work or home care

Rank 2: The patient's last $\mathrm{ED}^{\mathrm{b}}$ visit related to COPD occurred no less than 27.2 days ago and no more than 94.3 days ago AND the patient's COPD medication prescriptions in the past year included between 13 and 16 distinct medications AND the patient's last outpatient visit on COPD occurred no less than 82.4 days ago and no more than 327.6 days ago AND the patient's maximum percentage of neutrophils in the past year was $>76.5 \% \rightarrow$ the patient will probably have at least one severe COPD exacerbation in the following 12 months

The patient's last ED visit related to COPD occurred no less than 27.2 days ago and no more than 94.3 days ago

The patient's COPD medication prescriptions in the past year included between 13 and 16 distinct medications

The patient's last outpatient visit on COPD occurred no less than 82.4 days ago and no more than 327.6 days ago

The patient's maximum percentage of neutrophils in the past year was $>76.5 \%$
Having a recent ED visit related to COPD shows a need for better control of the disease.

Using many COPD medications can indicate an ineffective regimen, poor treatment adherence, or poor control of the disease.

If the patient's last outpatient visit on COPD was for acute problems with COPD, it could indicate poor control of the disease and a need for additional support to control COPD.

Having a large percentage of neutrophils can indicate infections or distress.
- Provide education on managing COPD and more frequent follow-ups

- Ensure use of appropriate COPD medications

- Consider influenza shot, pneumonia vaccination, or smoking cessation

- Assess the need for pulmonary rehabilitation or home care

- Ensure that the patient has a primary care provider or is referred to a specialist

- Simplify COPD medications to once-a-day formulations or combination medications

- Address concerns for adverse interactions between medications

- Provide education on the correct use of COPD medications or inhalers

- Consider strategies to improve medication adherence such as using a pill organizer or providing reminders for taking medications in time

- Medication reconciliation review by a physician or a pharmacist

- $\quad$ Provide education on managing COPD and resources for care

- Ensure use of appropriate COPD medications

- $\quad$ Assess the need for home care

- Evaluate the respiratory system, for example, using radiographic imaging

- Consider doing diagnostic tests such as viral panel, sputum culture, or procalcitonin

- Evaluate other potential morbidities such as cardiovascular disease with an electrocardiogram, echocardiography, or laboratory tests such as brain natriuretic peptide or D-dimer

Rank 3: The patient had between 8 and 19 diagnoses of acute COPD exacerbation in the past year AND the relative decline of the patient's BMI in the past year was $>0.44 \%$ AND the patient's total length of inpatient stays in the past year was $>0.6$ day $\rightarrow$ the patient will probably have at least one severe COPD exacerbation in the following 12 months

The patient had between 8 and 19 diagnoses of acute COPD exacerbation in the past year
Frequently having acute COPD exacerbations shows a need for better control of the disease.
Provide education on managing COPD and more frequent follow-ups Ensure use of appropriate COPD medications

- Consider influenza shot, pneumonia vaccination, or smoking cessation

- Assess the need for pulmonary rehabilitation or home care

- Ensure that the patient has a primary care provider or is referred to a specialist 


\begin{tabular}{|c|c|c|}
\hline $\begin{array}{l}\text { Rank, rule, and item on the } \\
\text { rule's left-hand side }\end{array}$ & Interpretation of the item & Interventions linked to the item \\
\hline $\begin{array}{l}\text { The relative decline of } \\
\text { the patient's BMI in the } \\
\text { past year was }>0.44 \%\end{array}$ & $\begin{array}{l}\text { Having an unintentional weight loss } \\
\text { can indicate comorbidities or other } \\
\text { complications, such as malnutrition or } \\
\text { metabolic syndrome. }\end{array}$ & $\begin{array}{l}\text { - Optimize nutritional status to address low BMI } \\
\text { - } \quad \text { Provide dietary education and advise appropriate exercise }\end{array}$ \\
\hline $\begin{array}{l}\text { The patient's total } \\
\text { length of inpatient stays } \\
\text { in the past year was } \\
>0.6 \text { day }\end{array}$ & $\begin{array}{l}\text { Having a long inpatient stay can indi- } \\
\text { cate that the patient has a more severe } \\
\text { disease or comorbidities. Having fre- } \\
\text { quent inpatient stays shows a need for } \\
\text { better control of the disease. }\end{array}$ & $\begin{array}{l}\text { - } \quad \text { Ensure that the patient has a primary care provider } \\
\text { - } \\
\text { - } \quad \text { Provide education on managing COPD and resources for care } \\
\text { - } \quad \text { Ensure use of appropriate COPD medications }\end{array}$ \\
\hline
\end{tabular}

${ }^{\mathrm{a} C O P D}$ : chronic obstructive pulmonary disease.

${ }^{\mathrm{b}} \mathrm{ED}$ : emergency department.

\section{Performance of the Automatic Explanation Method}

The automatic explanation method was evaluated using the test set. Our method explained the predictions for $97.1 \%$ (100/103) of the patients with COPD who were correctly predicted by our model to have severe COPD exacerbations in the following 12 months. For each such patient, our method gave an average of 13,880.19 (SD 18,700.60) explanations covering 39.80 (SD 11.98) distinct actionable items, a median of 4474 explanations, and a median of 41 distinct actionable items covered by the explanations. Each explanation corresponds to an association rule.

Figure 2. The distribution of the number of actionable rules matching a patient who was correctly predicted by our model to have $\geq 1$ severe chronic obstructive pulmonary disease exacerbation in the following 12 months.

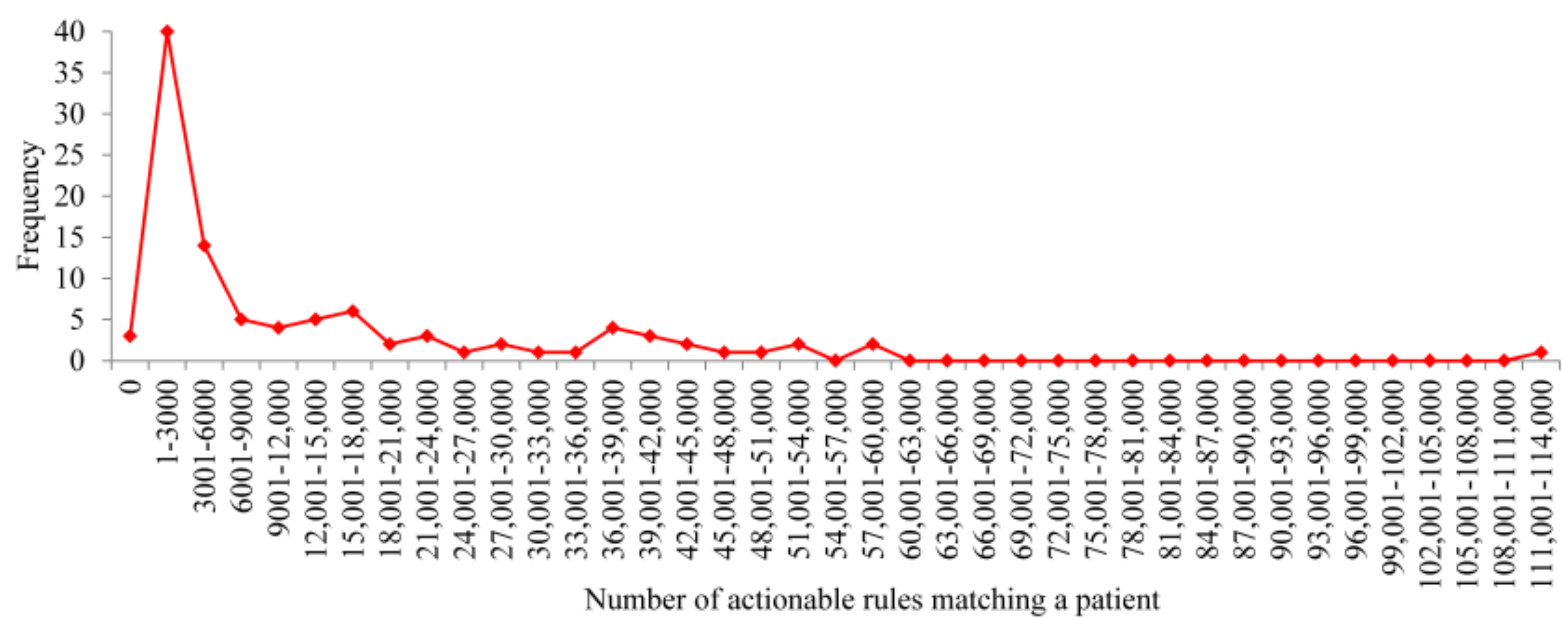

(a) When no limit is put on the number of actionable rules matching a patient.

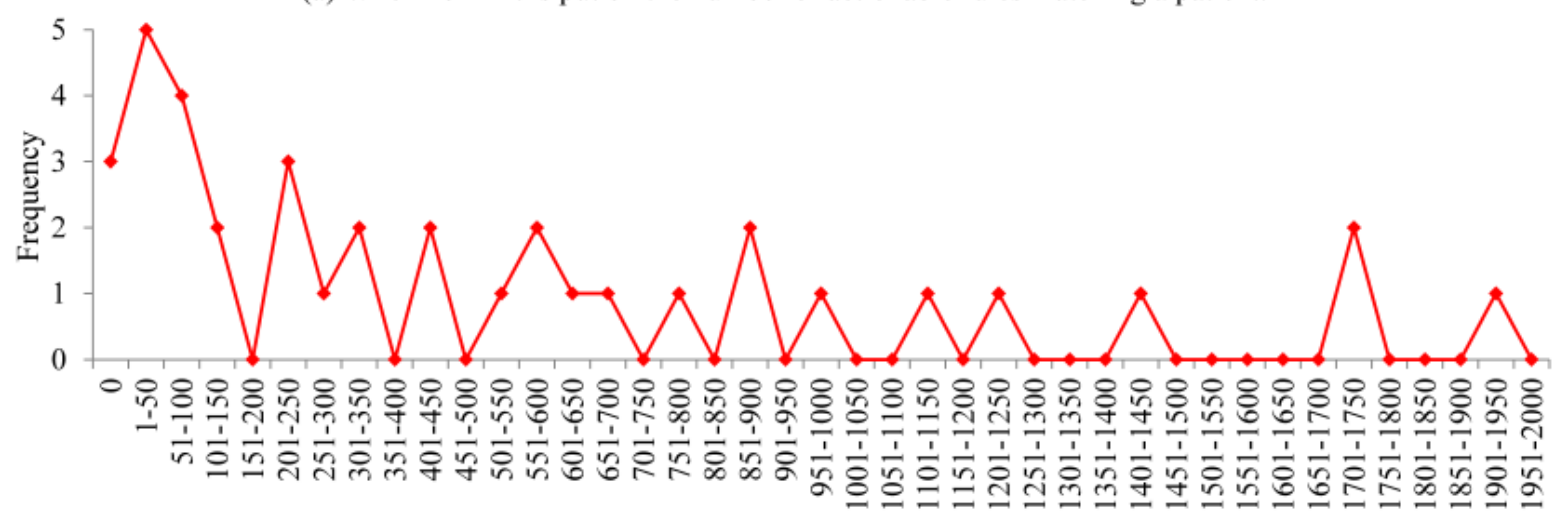

Number of actionable rules matching a patient

(b) When the number of actionable rules matching a patient is $\leq 2000$. 
For the patients with COPD who were correctly predicted by our model to have severe COPD exacerbations in the following 12 months, Figure 3 shows the distribution of the number of unique actionable items in the rules matching a patient. The largest number of unique actionable items in the rules matching a patient is 57 , which is much smaller than the largest number of actionable rules matching a patient. As shown in Tables 3-5, the same intervention could be linked to $\geq 1$ distinct actionable item in the rules matching a patient.

Figure 3. The distribution of the number of unique actionable items in the rules matching a patient who was correctly predicted by our model to have $\geq 1$ severe chronic obstructive pulmonary disease exacerbation in the following 12 months.

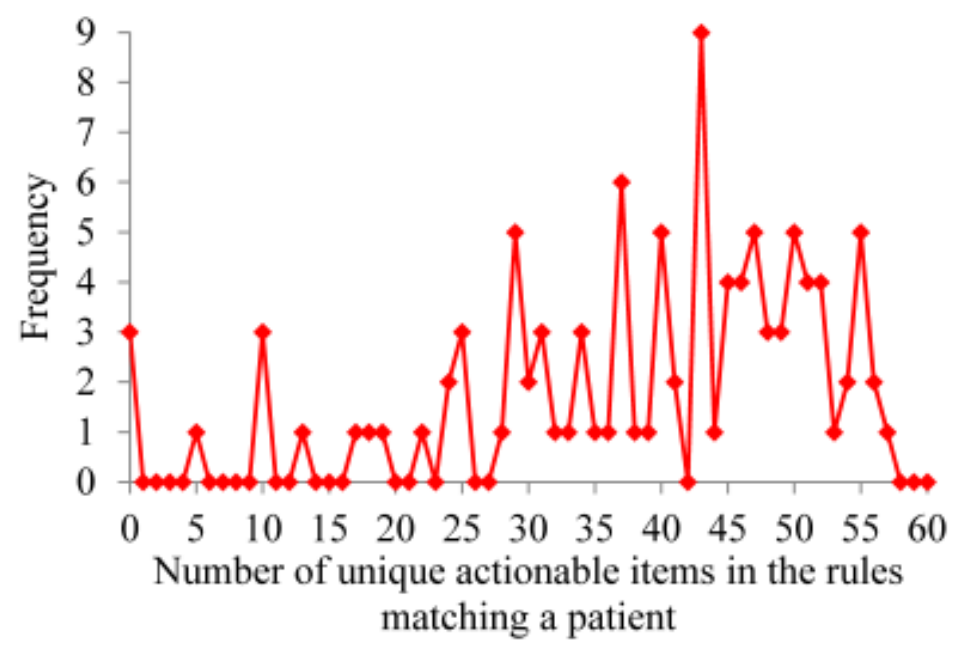

Our automatic explanation method explained the predictions for $73.6 \%(134 / 182)$ of the patients with COPD who had $\geq 1$ severe COPD exacerbation in the following 12 months.

\section{Discussion}

\section{Principal Findings}

Our automatic explanation method generalizes well in predicting severe COPD exacerbations. Our method explained the predictions for $97.1 \%(100 / 103)$ of the patients with COPD who were correctly predicted by our model to have severe COPD exacerbations in the following 12 months. This percentage is comparable with the corresponding percentages of $87.6 \%$ to $97.6 \%$ that we previously obtained to explain the predictions of asthma outcomes [54-56]. This percentage is sufficiently large to apply our automatic explanation method to routine clinical use for COPD management. After further improving the performance of our model for predicting severe COPD exacerbations and our automatic explanation method, we hope our model can be used in conjunction with our automatic explanation method to provide decision support for allocating COPD care management resources and improve outcomes.

Our automatic explanation method explained the predictions for $73.6 \%$ (134/182) of the patients with COPD who had $\geq 1$ severe COPD exacerbation in the following 12 months. This percentage is $<97.1 \%$ (100/103), the success rate at which our method explained the predictions for the patients with COPD whom our model correctly predicted to have severe COPD exacerbations in the following 12 months. This seems likely to be because of the correlation between the prediction results of our model and the association rules. Among the patients whom our model correctly predicted to have severe COPD exacerbations in the following 12 months, many seem to be easy cases for using association rules to explain the outcomes. Among the patients who had severe COPD exacerbations but were incorrectly predicted by our model to have no severe COPD exacerbation in the following 12 months, many seem to be difficult cases for any model to correctly predict or explain the outcomes.

\section{Related Work}

Several years ago, we designed our automatic explanation method to handle relatively balanced data and demonstrated our method for predicting the diagnosis of type 2 diabetes [58]. Later, other researchers demonstrated our method on several other clinical predictive modeling tasks, such as predicting lung transplantation or mortality in patients with cystic fibrosis [66] and predicting cardiac mortality in patients with cancer [67]. Recently, we extended our automatic explanation method so it can also handle imbalanced data, where one value of the outcome variable appears much less often than another. We demonstrated our extended method for predicting hospital encounters for asthma in patients with asthma in 3 health care systems separately [54-56]. Imbalanced data also appear in the case of predicting severe COPD exacerbations, which is the use case of this paper.

As discussed in the reviews [68,69], other researchers have developed a variety of methods to automatically explain the predictions made by machine learning models. Many of these methods lower the model performance or work only for a specific machine learning algorithm. Most of these methods provide explanations that are not of rule types. More importantly, none of these methods can automatically suggest tailored interventions, which is desired in many clinical applications. In comparison, our automatic explanation method has four properties that make it particularly suitable for providing clinical decision support: (1) it provides rule-type explanations, which are easier to understand than other kinds of explanations; (2) it works for any machine learning model on tabular data; (3) it does not lower model performance; and 
(4) it is the only automatic explanation method that can automatically suggest tailored interventions.

Rudin et al [70], Ribeiro et al [71], Rasouli et al [72], Pastor and Baralis [73], Guidotti et al [74], and Panigutti et al [75] used rules to automatically explain machine learning predictions. These rules are not known before the time of prediction, making it impossible to use them to automatically suggest tailored interventions at the time of prediction. Except for the case of Pastor and Baralis [73], these rules are not association rules. In comparison, our automatic explanation method mines association rules before the time of prediction and uses them to automatically suggest tailored interventions at the time of prediction.

\section{Limitations}

This study has 5 limitations that are worth addressing in future work.

First, this study used data from a single health care system. It is worth assessing our automatic explanation method's performance in explaining the predictions of severe COPD exacerbations in other health care systems.

Second, this study focuses on the prediction of one outcome-whether a patient with COPD will have $\geq 1$ severe COPD exacerbation in the following 12 months. It is worth assessing our automatic explanation method's performance in explaining the predictions of other outcomes.
Third, our automatic explanation method currently works for explaining the predictions that traditional non-deep-learning machine learning algorithms make on tabular data. It is worth investigating the extension of our method to handle the predictions made by deep learning models on longitudinal data [76,77].

Fourth, we currently know no optimal way to present automatic explanations and automatically suggested interventions. It is worth investigating an optimal way to present this information based on a user-centered design.

Finally, researchers have assessed the impact of automatic explanations on decision-making for several other applications [78-82] before but not for care management. For the automatic explanation function for predicting severe COPD exacerbations presented in this paper, it is worth assessing the impact of showing automatic explanations and automatically suggested interventions on care management enrollment and intervention decisions.

\section{Conclusions}

Our automatic explanation method generalizes well in predicting severe COPD exacerbations. After further improving the performance of our model for predicting severe COPD exacerbations and our automatic explanation method, we hope our model can be used in conjunction with our automatic explanation method to provide decision support for allocating COPD care management resources and improve outcomes.

\section{Acknowledgments}

GL and SZ were partially supported by the National Heart, Lung, and Blood Institute of the National Institutes of Health under award number R01HL142503. SZ was also partially supported by the National Library of Medicine Training Grant under award number T15LM007442. MA was partially supported by grants from the Flight Attendant Medical Research Institute (CIA190001) and the California Tobacco-Related Disease Research Program (T29IR0715). The funders had no role in the study design, data collection and analysis, decision to publish, or preparation of the manuscript.

\section{Authors' Contributions}

GL and SZ were mainly responsible for the paper. SZ conducted a literature review, performed most of the data analysis, and wrote the first draft of the paper. GL conceptualized and designed the study, participated in data analysis, and rewrote the entire paper. MA provided clinical expertise, contributed to conceptualizing the presentation, and revised the paper.

\section{Conflicts of Interest}

None declared.

\section{References}

1. Disease or condition of the week - COPD. Centers for Disease Control and Prevention. 2019. URL: https://www.cdc.gov/ dotw/copd/index.html [accessed 2021-11-14]

2. Ford ES, Murphy LB, Khavjou O, Giles WH, Holt JB, Croft JB. Total and state-specific medical and absenteeism costs of COPD among adults aged $\geq 18$ years in the United States for 2010 and projections through 2020. Chest 2015 Jan;147(1):31-45. [doi: 10.1378/chest.14-0972] [Medline: 25058738]

3. 2020 Gold Reports. Global Initiative for Chronic Obstructive Lung Disease - GOLD. 2020. URL: https://goldcopd.org/ gold-reports [accessed 2021-11-14]

4. Anzueto A, Leimer I, Kesten S. Impact of frequency of COPD exacerbations on pulmonary function, health status and clinical outcomes. Int J Chron Obstruct Pulmon Dis 2009;4:245-251 [FREE Full text] [doi: 10.2147/copd.s4862] [Medline: 19657398]

5. Connors Jr AF, Dawson NV, Thomas C, Harrell Jr FE, Desbiens N, Fulkerson WJ, et al. Outcomes following acute exacerbation of severe chronic obstructive lung disease. The SUPPORT investigators (Study to Understand Prognoses and 
Preferences for Outcomes and Risks of Treatments). Am J Respir Crit Care Med 1996 Oct;154(4 Pt 1):959-967. [doi: 10.1164/ajrccm.154.4.8887592] [Medline: 8887592 ]

6. Viglio S, Iadarola P, Lupi A, Trisolini R, Tinelli C, Balbi B, et al. MEKC of desmosine and isodesmosine in urine of chronic destructive lung disease patients. Eur Respir J 2000 Jun;15(6):1039-1045 [FREE Full text] [doi: 10.1034/j.1399-3003.2000.01511.x] [Medline: 10885422]

7. Kanner RE, Anthonisen NR, Connett JE, Lung Health Study Research Group. Lower respiratory illnesses promote FEV(1) decline in current smokers but not ex-smokers with mild chronic obstructive pulmonary disease: results from the lung health study. Am J Respir Crit Care Med 2001 Aug 01;164(3):358-364. [doi: 10.1164/ajrccm.164.3.2010017] [Medline: 11500333]

8. Spencer S, Jones PW, GLOBE Study Group. Time course of recovery of health status following an infective exacerbation of chronic bronchitis. Thorax 2003 Jul;58(7):589-593 [FREE Full text] [doi: 10.1136/thorax.58.7.589] [Medline: 12832673]

9. Spencer S, Calverley PM, Burge PS, Jones PW, ISOLDE (Inhaled Steroids in Obstructive Lung Disease) Study Group. Health status deterioration in patients with chronic obstructive pulmonary disease. Am J Respir Crit Care Med 2001 Jan;163(1):122-128. [doi: 10.1164/ajrccm.163.1.2005009] [Medline: 11208636]

10. Blanchette CM, Dalal AA, Mapel D. Changes in COPD demographics and costs over 20 years. J Med Econ 2012;15(6):1176-1182. [doi: 10.3111/13696998.2012.713880] [Medline: 22812689]

11. Johnston J, Longman J, Ewald D, King J, Das S, Passey M. Study of potentially preventable hospitalisations (PPH) for chronic conditions: what proportion are preventable and what factors are associated with preventable PPH? BMJ Open 2020 Nov 09;10(11):e038415 [FREE Full text] [doi: 10.1136/bmjopen-2020-038415] [Medline: $\underline{33168551]}$

12. Curry N, Billings J, Darin B, Dixon J, Williams M, Wennberg D. Predictive risk project literature review. King's Fund, London. 2005. URL: http://www.kingsfund.org.uk/sites/files/kf/field/field document/ predictive-risk-literature-review-june2005.pdf, [accessed 2021-11-14]

13. Mays GP, Claxton G, White J. Managed care rebound? Recent changes in health plans' cost containment strategies. Health Aff (Millwood) 2004;Suppl Web Exclusives:427-436 [FREE Full text] [doi: 10.1377/hlthaff.w4.427] [Medline: 15451964]

14. Bandurska E, Damps-Konstańska I, Popowski P, Jędrzejczyk T, Janowiak P, Swiętnicka K, et al. Impact of integrated care model (ICM) on direct medical costs in management of advanced chronic obstructive pulmonary disease (COPD). Med Sci Monit 2017 Jun 12;23:2850-2862 [FREE Full text] [doi: 10.12659/msm.901982] [Medline: 28603270]

15. Rice KL, Dewan N, Bloomfield HE, Grill J, Schult TM, Nelson DB, et al. Disease management program for chronic obstructive pulmonary disease: a randomized controlled trial. Am J Respir Crit Care Med 2010 Oct 1;182(7):890-896. [doi: 10.1164/rccm.200910-15790C] [Medline: 20075385]

16. Axelrod RC, Vogel D. Predictive modeling in health plans. Dis Manag Health Outcomes 2003;11(12):779-787. [doi: 10.2165/00115677-200311120-00003]

17. Zeng S, Arjomandi M, Tong Y, Liao ZC, Luo G. Developing a machine learning model to predict severe chronic obstructive pulmonary disease exacerbations: retrospective cohort study. J Med Internet Res 2022 Jan 06;24(1):e28953 [FREE Full text] [doi: 10.2196/28953] [Medline: 34989686]

18. Annavarapu S, Goldfarb S, Gelb M, Moretz C, Renda A, Kaila S. Development and validation of a predictive model to identify patients at risk of severe COPD exacerbations using administrative claims data. Int J Chron Obstruct Pulmon Dis 2018;13:2121-2130 [FREE Full text] [doi: 10.2147/COPD.S155773] [Medline: 30022818]

19. Tavakoli H, Chen W, Sin DD, FitzGerald JM, Sadatsafavi M. Predicting severe chronic obstructive pulmonary disease exacerbations. Developing a population surveillance approach with administrative data. Ann Am Thorac Soc 2020 Sep;17(9):1069-1076. [doi: 10.1513/AnnalsATS.202001-070OC] [Medline: 32383971]

20. Samp JC, Joo MJ, Schumock GT, Calip GS, Pickard AS, Lee TA. Predicting acute exacerbations in chronic obstructive pulmonary disease. J Manag Care Spec Pharm 2018 Mar;24(3):265-279. [doi: 10.18553/jmcp.2018.24.3.265] [Medline: 29485951]

21. Thomsen M, Ingebrigtsen TS, Marott JL, Dahl M, Lange P, Vestbo J, et al. Inflammatory biomarkers and exacerbations in chronic obstructive pulmonary disease. J Am Med Assoc 2013 Jun 12;309(22):2353-2361. [doi: 10.1001/jama.2013.5732] [Medline: 23757083]

22. Orchard P, Agakova A, Pinnock H, Burton CD, Sarran C, Agakov F, et al. Improving prediction of risk of hospital admission in chronic obstructive pulmonary disease: application of machine learning to telemonitoring data. J Med Internet Res 2018 Sep 21;20(9):e263 [FREE Full text] [doi: 10.2196/jmir.9227] [Medline: 30249589]

23. Suetomo M, Kawayama T, Kinoshita T, Takenaka S, Matsuoka M, Matsunaga K, et al. COPD assessment tests scores are associated with exacerbated chronic obstructive pulmonary disease in Japanese patients. Respir Investig 2014 Sep;52(5):288-295. [doi: 10.1016/j.resinv.2014.04.004] [Medline: 25169844]

24. Lee SD, Huang MS, Kang J, Lin CH, Park MJ, Oh YM, Investigators of the Predictive Ability of CAT in Acute Exacerbations of COPD (PACE) Study. The COPD assessment test (CAT) assists prediction of COPD exacerbations in high-risk patients. Respir Med 2014 Apr;108(4):600-608 [FREE Full text] [doi: 10.1016/j.rmed.2013.12.014] [Medline: 24456695]

25. Faganello MM, Tanni SE, Sanchez FF, Pelegrino NR, Lucheta PA, Godoy I. BODE index and GOLD staging as predictors of 1-year exacerbation risk in chronic obstructive pulmonary disease. Am J Med Sci 2010 Jan;339(1):10-14. [doi: 10.1097/MAJ.0b013e3181bb8111] [Medline: 19926966] 
26. Alcázar B, García-Polo C, Herrejón A, Ruiz LA, de Miguel J, Ros JA, et al. Factors associated with hospital admission for exacerbation of chronic obstructive pulmonary disease. Arch Bronconeumol 2012 Mar;48(3):70-76. [doi: 10.1016/j.arbres.2011.10.009] [Medline: 22196478 ]

27. Bertens LC, Reitsma JB, Moons KG, van Mourik Y, Lammers JW, Broekhuizen BD, et al. Development and validation of a model to predict the risk of exacerbations in chronic obstructive pulmonary disease. Int J Chron Obstruct Pulmon Dis 2013;8:493-499 [FREE Full text] [doi: 10.2147/COPD.S49609] [Medline: 24143086]

28. Miravitlles M, Guerrero T, Mayordomo C, Sánchez-Agudo L, Nicolau F, Segú JL. Factors associated with increased risk of exacerbation and hospital admission in a cohort of ambulatory COPD patients: a multiple logistic regression analysis. The EOLO Study Group. Respiration 2000;67(5):495-501. [doi: 10.1159/000067462] [Medline: 11070451]

29. Make BJ, Eriksson G, Calverley PM, Jenkins CR, Postma DS, Peterson S, et al. A score to predict short-term risk of COPD exacerbations (SCOPEX). Int J Chron Obstruct Pulmon Dis 2015;10:201-209 [FREE Full text] [doi: 10.2147/COPD.S69589] [Medline: 25670896]

30. Montserrat-Capdevila J, Godoy P, Marsal JR, Barbé F. Predictive model of hospital admission for COPD exacerbation. Respir Care 2015 Sep;60(9):1288-1294 [FREE Full text] [doi: $\underline{10.4187 / \text { respcare.04005] [Medline: 26286737] }}$

31. Kerkhof M, Freeman D, Jones R, Chisholm A, Price DB, Respiratory Effectiveness Group. Predicting frequent COPD exacerbations using primary care data. Int J Chron Obstruct Pulmon Dis 2015;10:2439-2450 [FREE Full text] [doi: 10.2147/COPD.S94259] [Medline: 26609229]

32. Chen X, Wang Q, Hu Y, Zhang L, Xiong W, Xu Y, et al. A nomogram for predicting severe exacerbations in stable COPD patients. Int J Chron Obstruct Pulmon Dis 2020;15:379-388 [FREE Full text] [doi: 10.2147/COPD.S234241] [Medline: $\underline{32110006}$

33. Yii AC, Loh CH, Tiew PY, Xu H, Taha AA, Koh J, et al. A clinical prediction model for hospitalized COPD exacerbations based on "treatable traits". Int J Chron Obstruct Pulmon Dis 2019;14:719-728 [FREE Full text] [doi: 10.2147/COPD.S194922] [Medline: $\underline{30988606}$ ]

34. Adibi A, Sin DD, Safari A, Johnson KM, Aaron SD, FitzGerald JM, et al. The Acute COPD Exacerbation Prediction Tool (ACCEPT): a modelling study. Lancet Respir Med 2020 Oct;8(10):1013-1021. [doi: 10.1016/S2213-2600(19)30397-2] [Medline: $\underline{32178776}$ ]

35. Stanford RH, Nag A, Mapel DW, Lee TA, Rosiello R, Vekeman F, et al. Validation of a new risk measure for chronic obstructive pulmonary disease exacerbation using health insurance claims data. Ann Am Thorac Soc 2016 Jul;13(7):1067-1075. [doi: 10.1513/AnnalsATS.201508-493OC] [Medline: 27070274]

36. Stanford RH, Nag A, Mapel DW, Lee TA, Rosiello R, Schatz M, et al. Claims-based risk model for first severe COPD exacerbation. Am J Manag Care 2018 Feb 01;24(2):45-53 [FREE Full text] [Medline: 29461849]

37. Stanford RH, Lau MS, Li Y, Stemkowski S. External validation of a COPD risk measure in a commercial and Medicare population: the COPD treatment ratio. J Manag Care Spec Pharm 2019 Jan;25(1):58-69. [doi: 10.18553/jmcp.2019.25.1.058] [Medline: 30589629]

38. Stanford RH, Korrer S, Brekke L, Reinsch T, Bengtson LG. Validation and assessment of the COPD treatment ratio as a predictor of severe exacerbations. Chronic Obstr Pulm Dis 2020 Jan;7(1):38-48 [FREE Full text] [doi: 10.15326/jcopdf.7.1.2019.0132] [Medline: 31999901]

39. Jones RC, Donaldson GC, Chavannes NH, Kida K, Dickson-Spillmann M, Harding S, et al. Derivation and validation of a composite index of severity in chronic obstructive pulmonary disease: the DOSE Index. Am J Respir Crit Care Med 2009 Dec 15;180(12):1189-1195. [doi: 10.1164/rccm.200902-02710C] [Medline: 19797160]

40. Jones RC, Price D, Chavannes NH, Lee AJ, Hyland ME, Ställberg B, UNLOCK Group of the IPCRG. Multi-component assessment of chronic obstructive pulmonary disease: an evaluation of the ADO and DOSE indices and the global obstructive lung disease categories in international primary care data sets. NPJ Prim Care Respir Med 2016 Apr 07;26:16010 [FREE Full text] [doi: 10.1038/npjpcrm.2016.10] [Medline: 27053297]

41. Fan VS, Curtis JR, Tu SP, McDonell MB, Fihn SD, Ambulatory Care Quality Improvement Project Investigators. Using quality of life to predict hospitalization and mortality in patients with obstructive lung diseases. Chest 2002 Aug;122(2):429-436. [doi: 10.1378/chest.122.2.429] [Medline: 12171813]

42. Moy ML, Teylan M, Danilack VA, Gagnon DR, Garshick E. An index of daily step count and systemic inflammation predicts clinical outcomes in chronic obstructive pulmonary disease. Ann Am Thorac Soc 2014 Feb;11(2):149-157. [doi: 10.1513/AnnalsATS.201307-2430C] [Medline: 24308588]

43. Briggs A, Spencer M, Wang H, Mannino D, Sin DD. Development and validation of a prognostic index for health outcomes in chronic obstructive pulmonary disease. Arch Intern Med 2008 Jan 14;168(1):71-79. [doi: 10.1001/archinternmed.2007.37] [Medline: 18195198]

44. Lange P, Marott JL, Vestbo J, Olsen KR, Ingebrigtsen TS, Dahl M, et al. Prediction of the clinical course of chronic obstructive pulmonary disease, using the new GOLD classification: a study of the general population. Am J Respir Crit Care Med 2012 Nov 15;186(10):975-981. [doi: 10.1164/rccm.201207-12990C] [Medline: 22997207]

45. Abascal-Bolado B, Novotny PJ, Sloan JA, Karpman C, Dulohery MM, Benzo RP. Forecasting COPD hospitalization in the clinic: optimizing the chronic respiratory questionnaire. Int J Chron Obstruct Pulmon Dis 2015;10:2295-2301 [FREE Full text] [doi: 10.2147/COPD.S87469] [Medline: 26543362] 
46. Blanco-Aparicio M, Vázquez I, Pita-Fernández S, Pértega-Diaz S, Verea-Hernando H. Utility of brief questionnaires of health-related quality of life (Airways Questionnaire 20 and Clinical COPD Questionnaire) to predict exacerbations in patients with asthma and COPD. Health Qual Life Outcomes 2013 May 27;11:85 [FREE Full text] [doi: 10.1186/1477-7525-11-85] [Medline: 23706146]

47. Yoo JW, Hong Y, Seo JB, Chae EJ, Ra SW, Lee JH, et al. Comparison of clinico-physiologic and CT imaging risk factors for COPD exacerbation. J Korean Med Sci 2011 Dec;26(12):1606-1612 [FREE Full text] [doi: 10.3346/jkms.2011.26.12.1606] [Medline: 22147998]

48. Niewoehner DE, Lokhnygina Y, Rice K, Kuschner WG, Sharafkhaneh A, Sarosi GA, et al. Risk indexes for exacerbations and hospitalizations due to COPD. Chest 2007 Jan;131(1):20-28. [doi: 10.1378/chest.06-1316] [Medline: 17218552]

49. Austin PC, Stanbrook MB, Anderson GM, Newman A, Gershon AS. Comparative ability of comorbidity classification methods for administrative data to predict outcomes in patients with chronic obstructive pulmonary disease. Ann Epidemiol 2012 Dec;22(12):881-887 [FREE Full text] [doi: 10.1016/j.annepidem.2012.09.011] [Medline: 23121992]

50. Marin JM, Carrizo SJ, Casanova C, Martinez-Camblor P, Soriano JB, Agusti AG, et al. Prediction of risk of COPD exacerbations by the BODE index. Respir Med 2009 Mar;103(3):373-378 [FREE Full text] [doi: 10.1016/j.rmed.2008.10.004] [Medline: 19013781$]$

51. Ställberg B, Lisspers K, Larsson K, Janson C, Müller M, Łuczko M, et al. Predicting hospitalization due to COPD exacerbations in Swedish primary care patients using machine learning - based on the ARCTIC study. Int J Chron Obstruct Pulmon Dis 2021;16:677-688 [FREE Full text] [doi: 10.2147/COPD.S293099] [Medline: $\underline{33758504}$ ]

52. Chen T, Guestrin C. XGBoost: a scalable tree boosting system. In: Proceedings of the ACM SIGKDD International Conference on Knowledge Discovery and Data Mining. 2016 Presented at: KDD'16: The 22nd ACM SIGKDD International Conference on Knowledge Discovery and Data Mining; August 13-17, 2016; San Francisco, CA p. 785-794. [doi: $10.1145 / 2939672.2939785]$

53. U.S. healthcare leaders expect widespread adoption of artificial intelligence by 2023. Intel. 2018. URL: https://newsroom. intel.com/news-releases/u-s-healthcare-leaders-expect-widespread-adoption-artificial-intelligence-2023 [accessed 2021-11-14]

54. Luo G, Johnson MD, Nkoy FL, He S, Stone BL. Automatically explaining machine learning prediction results on asthma hospital visits in patients with asthma: secondary analysis. JMIR Med Inform 2020 Dec 31;8(12):e21965 [FREE Full text] [doi: 10.2196/21965] [Medline: 33382379]

55. Tong Y, Messinger AI, Luo G. Testing the generalizability of an automated method for explaining machine learning predictions on asthma patients' asthma hospital visits to an academic healthcare system. IEEE Access 2020;8:195971-195979 [FREE Full text] [doi: 10.1109/access.2020.3032683] [Medline: 33240737]

56. Luo G, Nau CL, Crawford WW, Schatz M, Zeiger RS, Koebnick C. Generalizability of an automatic explanation method for machine learning prediction results on asthma-related hospital visits in patients with asthma: quantitative analysis. J Med Internet Res 2021 Apr 15;23(4):e24153 [FREE Full text] [doi: 10.2196/24153] [Medline: 33856359]

57. Zhang X, Luo G. Ranking rule-based automatic explanations for machine learning predictions on asthma hospital encounters in patients with asthma: retrospective cohort study. JMIR Med Inform 2021 Aug 11;9(8):e28287 [FREE Full text] [doi: 10.2196/28287] [Medline: 34383673]

58. Luo G. Automatically explaining machine learning prediction results: a demonstration on type 2 diabetes risk prediction. Health Inf Sci Syst 2016;4:2 [FREE Full text] [doi: 10.1186/s13755-016-0015-4] [Medline: 26958341]

59. NQF \#1891 Hospital 30-day, all-cause, risk-standardized readmission rate (RSRR) following chronic obstructive pulmonary disease (COPD) hospitalization. National Quality Forum. 2012. URL: http://www.qualityforum.org/Projects/n-r/ Pulmonary Endorsement Maintenance/1891 30 Day RSRR COPD.aspx [accessed 2021-11-14]

60. Cooke CR, Joo MJ, Anderson SM, Lee TA, Udris EM, Johnson E, et al. The validity of using ICD-9 codes and pharmacy records to identify patients with chronic obstructive pulmonary disease. BMC Health Serv Res 2011 Feb 16;11:37 [FREE Full text] [doi: 10.1186/1472-6963-11-37] [Medline: 21324188]

61. Nguyen HQ, Chu L, Amy Liu LI, Lee JS, Suh D, Korotzer B, et al. Associations between physical activity and 30-day readmission risk in chronic obstructive pulmonary disease. Ann Am Thorac Soc 2014 Jun;11(5):695-705. [doi: 10.1513/AnnalsATS.201401-0170C] [Medline: 24713094]

62. Lindenauer PK, Grosso LM, Wang C, Wang Y, Krishnan JA, Lee TA, et al. Development, validation, and results of a risk-standardized measure of hospital 30-day mortality for patients with exacerbation of chronic obstructive pulmonary disease. J Hosp Med 2013 Aug;8(8):428-435. [doi: 10.1002/jhm.2066] [Medline: 23913593]

63. Liu B, Hsu W, Ma Y. Integrating classification and association rule mining. In: Proceedings of the 4th International Conference on Knowledge Discovery and Data Mining. 1998 Presented at: KDD'98: Fourth International Conference on Knowledge Discovery and Data Mining; August 27-31, 1998; New York City, NY, USA p. 80-86 URL: https://dl.acm.org/ doi/10.5555/3000292.3000305

64. Thabtah FA. A review of associative classification mining. Knowledge Eng Review 2007 Mar 01;22(1):37-65. [doi: $10.1017 / \mathrm{s} 0269888907001026]$

65. Fayyad UM, Irani KB. Multi-interval discretization of continuous-valued attributes for classification learning. In: Proceedings of the 13th International Joint Conference on Artificial Intelligence. 1993 Presented at: IJCAI'93: 13th International Joint 
Conference on Artificial Intelligence; August 28-September 3, 1993; Chambéry, France p. 1022-1029 URL: https://trs. jpl.nasa.gov/handle/2014/35171

66. Alaa AM, van der Schaar M. Prognostication and risk factors for cystic fibrosis via automated machine learning. Sci Rep 2018 Jul 26;8(1):11242 [FREE Full text] [doi: 10.1038/s41598-018-29523-2] [Medline: 30050169]

67. Alaa AM, van der Schaar M. AutoPrognosis: automated clinical prognostic modeling via Bayesian optimization with structured kernel learning. In: Proceedings of the 35th International Conference on Machine Learning. 2018 Presented at: ICML'18: 35th International Conference on Machine Learning; July 10-15, 2018; Stockholm, Sweden p. 139-148 URL: https://arxiv.org/abs/1802.07207

68. Guidotti R, Monreale A, Ruggieri S, Turini F, Giannotti F, Pedreschi D. A survey of methods for explaining black box models. ACM Comput Surv 2019 Sep 30;51(5):93. [doi: 10.1145/3236009]

69. Payrovnaziri SN, Chen Z, Rengifo-Moreno P, Miller T, Bian J, Chen JH, et al. Explainable artificial intelligence models using real-world electronic health record data: a systematic scoping review. J Am Med Inform Assoc 2020 Jul 01;27(7):1173-1185 [FREE Full text] [doi: 10.1093/jamia/ocaa053] [Medline: 32417928]

70. Rudin C, Shaposhnik Y. Globally-consistent rule-based summary-explanations for machine learning models: application to credit-risk evaluation. In: Proceedings of INFORMS 11th Conference on Information Systems and Technology. 2019 Presented at: CIST'19: INFORMS 11th Conference on Information Systems and Technology; October 19-20, 2019; Seattle, WA p. 1-19. [doi: $10.2139 /$ ssrn.3395422]

71. Ribeiro MT, Singh S, Guestrin C. Anchors: high-precision model-agnostic explanations. In: Proceedings of the 32nd AAAI Conference on Artificial Intelligence. 2018 Presented at: AAAI'18: 32nd AAAI Conference on Artificial Intelligence; February 2-7, 2018; New Orleans, LA p. 1527-1535 URL: https://ojs.aaai.org/index.php/AAAI/article/view/11491

72. Rasouli P, Yu IC. EXPLAN: explaining black-box classifiers using adaptive neighborhood generation. In: Proceedings of the 2020 International Joint Conference on Neural Networks. 2020 Presented at: IJCNN'20: International Joint Conference on Neural Networks; July 19-24, 2020; Glasgow, UK p. 1-9. [doi: 10.1109/ijcnn48605.2020.9206710]

73. Pastor E, Baralis E. Explaining black box models by means of local rules. In: Proceedings of the 34th ACM/SIGAPP Symposium on Applied Computing. 2019 Presented at: SAC'19: The 34th ACM/SIGAPP Symposium on Applied Computing; April 8-12, 2019; Limassol, Cyprus p. 510-517. [doi: 10.1145/3297280.3297328]

74. Guidotti R, Monreale A, Ruggieri S, Pedreschi D, Turini F, Giannotti F. Local rule-based explanations of black box decision systems. arXiv. 2018. URL: https://arxiv.org/abs/1805.10820 [accessed 2021-11-14]

75. Panigutti C, Perotti A, Pedreschi D. Doctor XAI: an ontology-based approach to black-box sequential data classification explanations. In: Proceedings of the Conference on Fairness, Accountability, and Transparency. 2020 Presented at: FAT'20: Conference on Fairness, Accountability, and Transparency; January 27-30, 2020; Barcelona, Spain p. 629-639. [doi: 10.1145/3351095.3372855]

76. Luo G, Stone BL, Koebnick C, He S, Au DH, Sheng X, et al. Using temporal features to provide data-driven clinical early warnings for chronic obstructive pulmonary disease and asthma care management: protocol for a secondary analysis. JMIR Res Protoc 2019 Jun 06;8(6):e13783 [FREE Full text] [doi: 10.2196/13783] [Medline: 31199308]

77. Luo G. A roadmap for semi-automatically extracting predictive and clinically meaningful temporal features from medical data for predictive modeling. Glob Transit 2019;1:61-82 [FREE Full text] [doi: 10.1016/j.glt.2018.11.001] [Medline: 31032483]

78. Weerts HJ, van Ipenburg W, Pechenizkiy M. A human-grounded evaluation of SHAP for alert processing. arXiv. 2019. URL: https://arxiv.org/abs/1907.03324 [accessed 2021-11-14]

79. Stites MC, Nyre-Yu M, Moss B, Smutz C, Smith MR. Sage advice? The impacts of explanations for machine learning models on human decision-making in spam detection. In: Proceedings of the Second International Conference on Artificial Intelligence in HCI. 2021 Presented at: AI-HCI'21: International Conference on Artificial Intelligence in HCI; July 24-29, 2021; Washington DC p. 269-284. [doi: 10.1007/978-3-030-77772-2 18]

80. Lai V, Tan C. On human predictions with explanations and predictions of machine learning models: a case study on deception detection. In: Proceedings of the Conference on Fairness, Accountability, and Transparency. 2019 Presented at: FAT'19: Conference on Fairness, Accountability, and Transparency; January 29-31, 2019; Atlanta, GA p. 29-38. [doi: $10.1145 / 3287560.3287590]$

81. Lundberg SM, Nair B, Vavilala MS, Horibe M, Eisses MJ, Adams T, et al. Explainable machine-learning predictions for the prevention of hypoxaemia during surgery. Nat Biomed Eng 2018 Oct;2(10):749-760 [FREE Full text] [doi: 10.1038/s41551-018-0304-0] [Medline: 31001455]

82. Jesus SM, Belém C, Balayan V, Bento J, Saleiro P, Bizarro P, et al. How can I choose an explainer? An application-grounded evaluation of post-hoc explanations. In: Proceedings of the 2021 ACM Conference on Fairness, Accountability, and Transparency. 2021 Presented at: FAccT'21: 2021 ACM Conference on Fairness, Accountability, and Transparency; March 3-10, 2021; Toronto, Canada p. 805-815. [doi: 10.1145/3442188.3445941]

\author{
Abbreviations \\ COPD: chronic obstructive pulmonary disease
}


ED: emergency department

UWM: University of Washington Medicine

XGBoost: extreme gradient boosting

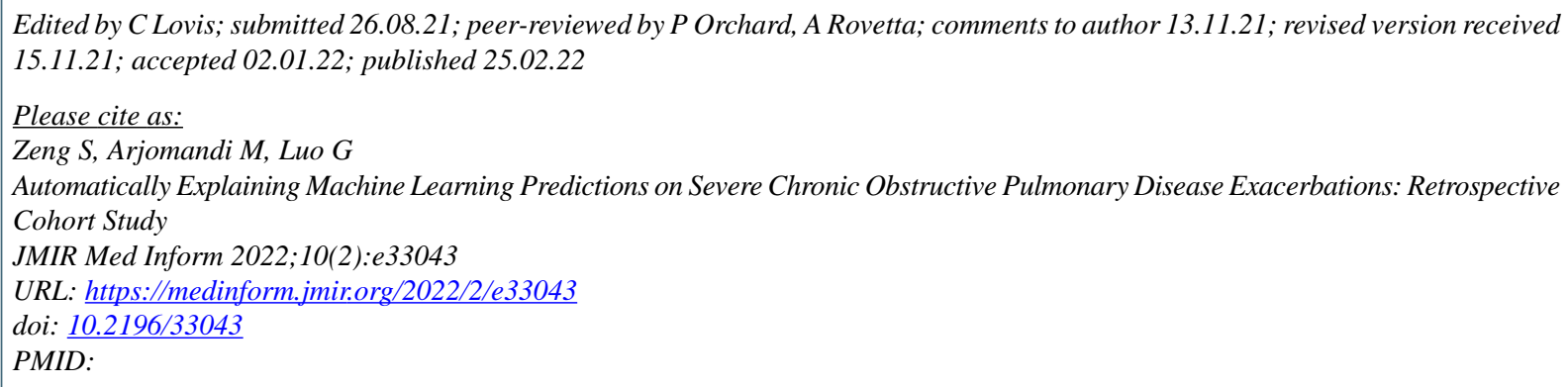

(C) Siyang Zeng, Mehrdad Arjomandi, Gang Luo. Originally published in JMIR Medical Informatics (https://medinform.jmir.org), 25.02.2022. This is an open-access article distributed under the terms of the Creative Commons Attribution License (https://creativecommons.org/licenses/by/4.0/), which permits unrestricted use, distribution, and reproduction in any medium, provided the original work, first published in JMIR Medical Informatics, is properly cited. The complete bibliographic information, a link to the original publication on https://medinform.jmir.org/, as well as this copyright and license information must be included. 